\section{A Abordagem do Uso Excessivo de Videojogos nos Cuidados de Saúde Primários}

An Approach to the Excessive Use of Videogaming in Primary Health Care

Palavras-chave: Comportamento Aditivo; Cuidados de Saúde Primários; Vídeojogos

Keywords: Behavior, Addictive; Primary Health Care; Video Games

Caro Editor, foi com grande interesse que li o artigo "Dependência de Videojogos: Um Problema Pediátrico Emergente?"1 publicado na Acta Médica Portuguesa no número de março de 2019. Este artigo, que se propõe a avaliar a prevalência da dependência de videojogos num grupo de crianças e identificar fatores protetores, de risco e potenciais consequências deste comportamento, é extremamente pertinente, quer pela sua frequência quer pelas potenciais consequências associadas.

É, de facto, urgente promover a consciencialização em relação aos riscos de uma utilização excessiva dos videojogos, incitando hábitos saudáveis e potenciando os benefícios desta atividade. Assim, de forma a alcançar este objetivo considero que este assunto deveria estar cada vez mais presente entre os temas discutidos na consulta de saúde infantil e juvenil desenvolvida pelo Médico de Família.

$\mathrm{O}$ artigo demonstra que uma importante percentagem da população estudada se encontra em risco de dependência, pelo que impera a prevenção. Esta poderá ser desenvolvida no contexto dos Cuidados de Saúde Primários, respeitando a importância da aplicação de cuidados anteci- patórios. Só através da promoção da saúde e prevenção da doença baseadas no aumento da literacia dos pais/cuidadores se conseguirá reduzir a incidência e prevalência da dependência deste tipo de jogos.

É então importante informar os pais e as crianças/jovens, sobre os riscos da sobreutilização dos videojogos, nomeadamente: obesidade, problemas do sono, problemas de desenvolvimento (nomeadamente atrasos cognitivos, de linguagem e sociais/emocionais), diminuição da interação pais/filhos, síndrome de hiperatividade e défice de atenção, redução do rendimento académico e aumento do abandono escolar, aumento das interações agressivas nas crianças mais jovens, especialmente nos rapazes, assim como lacunas na adaptação social, uma vez que estas crianças se encontram em risco de não desenvolverem capacidades importantes nesse contexto..$^{2-4}$

Este trabalho revela ainda a necessidade de validação de questionários adaptados a este problema que permitam uma avaliação precisa e que sustentem intervenções neste âmbito.

O Médico de Família encontra-se numa posição privilegiada para abordar este problema, sendo cada vez mais necessário uma adaptação a esta nova realidade no sentido de interpelar a criança e família acerca dos hábitos relacionados com os videojogos. Esta abordagem deve pautar-se pela promoção da responsabilização dos pais pela gestão do tempo despendido nesta atividade, e transmitir os riscos associados, elucidando acerca das vantagens da prática de atividades alternativas e que estimulem as várias vertentes do seu desenvolvimento, adaptando-as aos interesses de cada criança e às possibilidades de cada família.

\title{
REFERÊNCIAS
}

1. Nogueira M, Faria H, Vitorino A, Silva FG, Neto AS. Addictive video game use: an emerging pediatric problem?. Acta Med Port. 2019;32:183-8.

2. American Academy of Pediatrics, council on communications and media. Media and young minds. Pediatrics. 2016;138:e20162591.

3. Arab E, Díaz A. Impacto de las redes sociales e internet en la

adolescencia: aspectos positivos $\mathrm{Y}$ negativos. Rev Med Clin Condes. 2015;26:7-13.

4. Browne KD, Hamilton-Giachritsis $C$. The influence of violent media on children and adolescents:a public-health approach. Lancet. 2005;365:702-10.

\section{Catarina Ramos RODRIGUES $\square^{1}$}

1. Unidade Saúde Familiar Eça de Queirós. Póvoa de Varzim..Portugal.

Autor correspondente: Catarina Ramos Rodrigues. catarinarodrigues41@hotmail.com

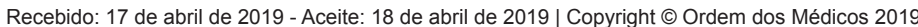

https://doi.org/10.20344/amp.12175 